\title{
Application of Artificial Intelligence in Precision Marketing
}

\author{
Xue Yang, North China University of Water Resources and Electric Power, China \\ Haowen Li, School of Management and Economics, North China University of Water Resources and Electric Power, China \\ Likun Ni, School of Management and Economics, North China University of Water Resources and Electric Power, China \\ Teng Li, School of Management engineering, Zhengzhou University, China
}

\begin{abstract}
The development of artificial intelligence technology has greatly helped social productivity and economic growth. At the same time, we have changed modern marketing methods, provided technical assistance for precision marketing, improved modern marketing efficiency, and effectively reduced marketing costs. Compared to traditional marketing, artificial intelligence technology is applied to accurate marketing activities. It will make the marketing effect more accurate and personalized. Faced with these technological advances, it is important to study the application of artificial intelligence technology for the precise new marketing model. The advancement of artificial intelligence technology not only changed the way of marketing activities, but also enabled marketers to attract consumers more effectively. The enormous amount of data provides new opportunities and challenges for marketers. AI technology can accurately identify customer needs in a huge database to locate potential customers, meet customer needs, and establish a good relationship between marketers and consumers.
\end{abstract}

\section{KEYWORDS}

Artificial Intelligence-Technology, Market Recommend-Dation, Precision Marketing

\section{INTRODUCTION}

Describe the general perspective of the article. End by specifically stating the objectives of the article. Artificial intelligence is a new technological science that researches and develops theories, methods, technologies, and application systems for simulating, extending, and expanding human intelligence. The research results have covered various areas and made the work more efficient (Canevelli,2019; Chen, 2019; Chang,2019; Kim, 2019).

Information technology is developing rapidly. The use of science and technology can analyze consumer user groups and consumer markets from the databases generated by consumers' online browsing traces and shopping records in major networks, find demand points and the best marketing time, and use artificial intelligence to understand customers (Macera, 2019; Mayor,2019). To understand the different needs of customers, when marketing and demand match, you can achieve marketing purposes and turn potential customers into actual customers. This will be a great way for artificial intelligence to help achieve successful marketing.

Precise marketing is mainly based on grasping consumer information data, such as user's personal information, searching, browsing records, etc. to mine customer preferences, conduct consumer positioning, and use modern computer technology to push more accurate and personalized 
relevant advertising content to customers. To establish a service system for customer communication (O’Connor, 2019).

The value embodied by precision is particularly obvious in contemporary marketing. Customers expect to minimize costs when buying. Precision marketing can not only reduce the purchase cost of customers but also increase the total value of customers. In modern e-commerce, the company is customer-centric. Customized solutions for customers can shorten the distance with customers, better communicate with customers back and forth, and form customer loyalty in a business environment. Enterprises not only need to make customers purchase products, but also need to ensure the purchase rate and return rate of recommendation rate. (Yezekyan, 2018; Yuning,2020) The formation of a good brand image requires greater efforts under precise marketing, which will make the company last long. Precision marketing can achieve a win-win situation for businesses and consumers. Precision distribution mainly includes four parts: Right-consumer, Right-channel, Right-message, Right-time.

Figure 1. Framework of precision consumption

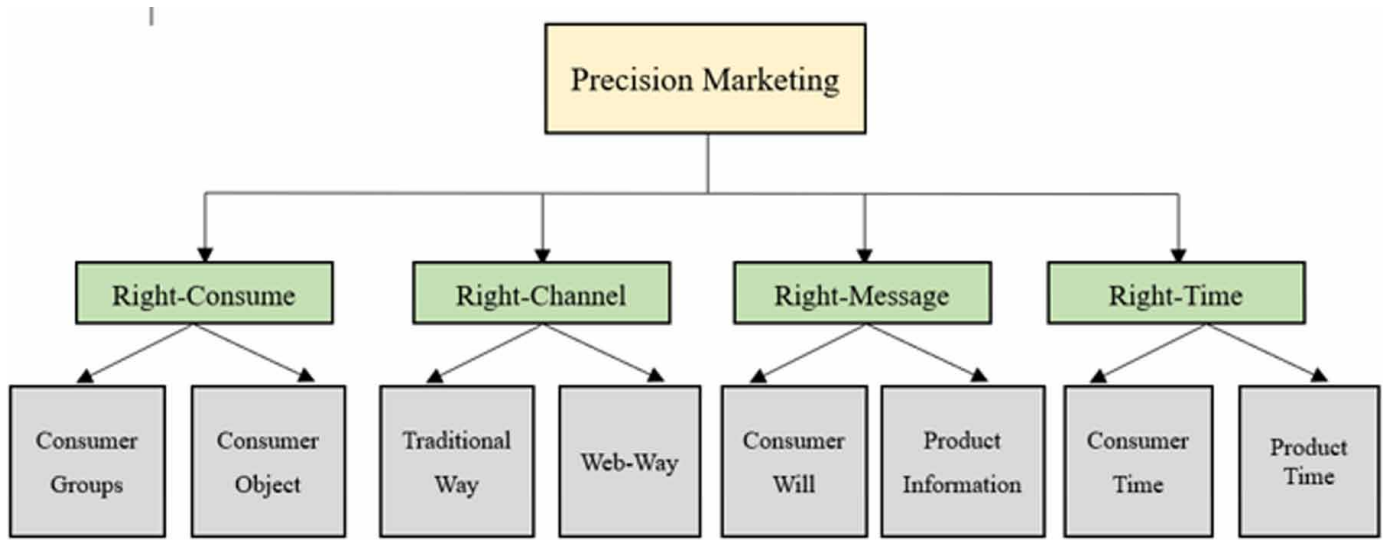

For consumers, service and experience are the topics they pay attention to. Whether it is online shopping or offline shopping, consumers are more eager to satisfy when they are engaged in consumer activities. Precision marketing under artificial intelligence technology can guide consumers' personal information and preferences technically, helping customers save shopping time, save costs, and bring about a better service experience. Through artificial intelligence information processing, each record will classify and distinguish consumers, and accurately and detailedly record and track consumer consumption records, including consumption time, consumption motivation, communication process, and after-sales feedback, forming a one-to-one Service data even knows more about consumers than consumers, in order to meet consumers' increasing expectations for brand interaction.

For advertisers, the moment when countless web pages and countless users browse a certain page is equivalent to a complex purchase training. "The dramatic increase in websites over the past 10 years has resulted in fragmented media. In order to meet the needs of marketers and purchase the necessary advertising space, it has become increasingly difficult for buyers to manage a large number of independent publishers." Forrester. Analysts Joanna O'Connell and Michael Greene say so. In addition, online media is highly time-sensitive (Raad, 2019). Regardless of the quality of online publishers and their expectations of getting a premium, they have a strong incentive to sell what they have at hand. It is only possible to show ads to users when they are browsing the web. At the moment, the user may click away, and the traditional advertising method is difficult to achieve the purpose of precision marketing. And the precision marketing under AI technology can instantly feedback to 
the merchant through the real-time records browsed by the user to help the merchant understand the consumer and push the product information required by the consumer to achieve the optimal effect of the push. The era of AI marketing has arrived. The development of technology has provided greater help for marketing. In the process of marketing, artificial intelligence technology can be applied, which can not only reduce marketing costs, realize innovation in marketing activities, but also enable marketers. The dynamics of customer interaction are more active, truly understand customers from customer feedback data, analyze the differences between different customer preferences, set up different labels, and conduct precise marketing to achieve the best results.

\section{Related Research}

Provide broad definitions and discussions of the topic and incorporate views of others (literature review) into the discussion to support, refute, or demonstrate your position on the topic. The traditional marketing strategy is the $4 \mathrm{P}$ combination proposed by Professor McCarthy, namely product, price, channel and promotion. In the past, the company paid more attention to the ultimate benefit, and did not put the needs of customers first to think about the problems that customers have, such as the time cost and money cost of searching for products. (Kumar, 2018; Lin, 2019) Secondly, in the traditional marketing model, consumers often need to go through many links to achieve from the production of the product to the receipt of the product. On the one hand, it increases the unnecessary expenses of many enterprises, and on the other hand, it increases the cost borne by consumers.

From the perspective of advertising methods, in the past, companies controlled the consumer experience and the way, content, time and place to interact with the brand. Consumers are now aware of new products in magazine or newspaper ads. They show advertisers' compelling commercials on their favorite TV shows. In the digital age, at first, it slowly started. As the computer scaled down, the driving force for growth and the popularity index increased, the speed of change accelerated, and the Internet became a place for brands to show their products to consumers. The phone has transformed into an always-connected global beacon, and it has now become a practical extension of our own, with consumers beginning to use social media as a primary means of interacting with each other and with brands. The successful digital age of having email in the mobile first world is also the "information" era, with the amount of available information increasing and media technology changing. As consumers are more willing to share data, consumers also expect more. The traditional advertising model is not obvious in sales, especially the rapid development of the Internet, and the role of TV advertising has weakened. Artificial intelligence marketing in the new era will win the favor of customers and achieve sustained long-term success. Injecting science and technology into marketing will help create a better future (Sharma, 2018; Xie, 2019).

The current wave of artificial intelligence has swept the world, and companies in the field of artificial intelligence are also exploding. By the beginning of 2016, there were 957 artificial intelligence companies in the world, covering 13 sub-sectors such as deep learning, machine vision, natural language understanding, etc. The global artificial intelligence market size was USD 7.45 billion in 2015. It is estimated that between 2017 and 2020 USD 10.7 billion to 18.3 billion, with a CAGR of approximately 20\%. In 2015, the size of China's artificial intelligence market was 1.2 billion yuan, and it is estimated that it will be about 2.7 billion to 9.1 billion yuan from 2017 to 2020 , with a compound annual average growth rate of about $50 \%$.

It can be seen from the chart data that the scale of artificial intelligence is constantly expanding. The proportion of China's artificial intelligence companies in the world has also continued to increase.

Artificial intelligence technology provides more effective marketing methods, shortens the actual marketing time and makes work more efficient. When the Internet was just popular, consumers relied on a single advertising medium, television ads, radio, newspapers, etc., in the consumption plan's existence and implementation. In many cases, advertisements faced the general public and did not subdivide them. Do accurate marketing. With the advancement of the Internet and the increase in popularity, consumer personalization has been differentiated. Consumers 'consumer preferences can 
Figure 2. The artificial intelligence market size and forecast are shown in the following chart

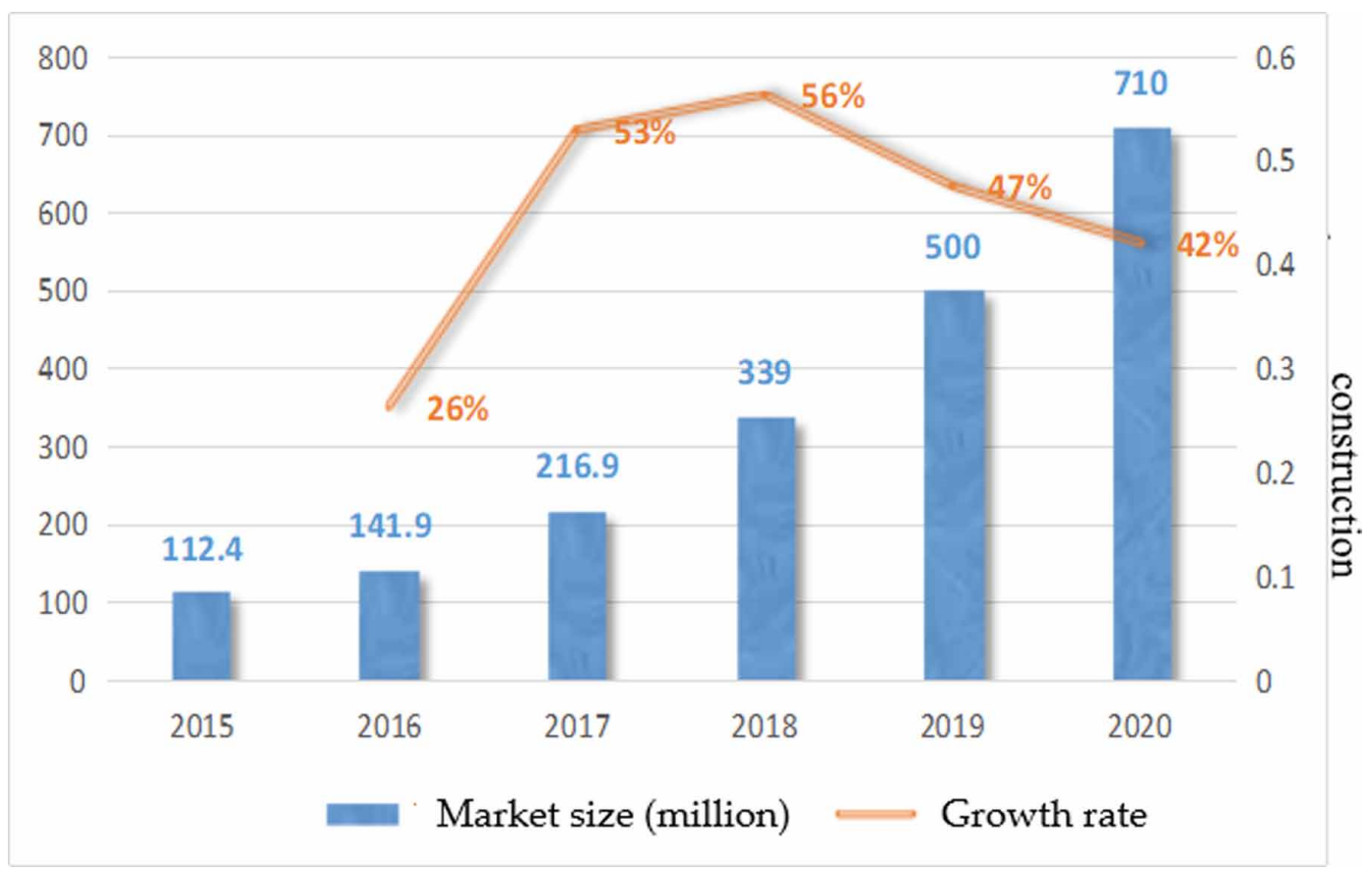

be extracted from technology. For example, Taobao uses artificial intelligence technology to apply customers' browsing records and purchase records Data and push related product information from customer's personal information, age, gender, hobbies to form customer portraits, and can associate other products that may generate consumer desires from a purchased product, and carry out a wider range of accurate push Compared with the traditional viral delivery, the form of advertising push under modern technology is more popular with consumers. When online push content is required by customers, it will increase the customer 's favor and promote purchase. Each major video player software also records the customer's viewing history and recommends their favorite videos, which can save customers' thinking time, and at the same time improve the brand image and form customer loyalty.

The ultimate goal of precision marketing is to help companies make money, but its immediate purpose is to help managers make judgments. As the world's top sports brand, Nike has many product categories. Nike shoes, Nike sportswear, and Nike sports equipment are all hot products on the market. As soon as a new product is listed, it will immediately trigger a hot snap. So, how does Nike ensure that every product is welcome? It uses a collection app that is unique to its own brand. On this software, as long as the user opens the interface, you can see the open data of all Nike products, including materials, environmental protection index, weight, air permeability and other attributes, all at a glance. These data are publicized, and consumers can intuitively feel Nike's sincerity, and are willing to personally participate in the development of new product suggestions through the APP. They can click to vote to express their expectations for new products. Finally, when gathering information, Nike can get a very simple and easy-to-understand pie chart that represents the percentage of consumer expectations. For example, a new running shoe, more than $60 \%$ of people voted "portable", $30 \%$ of people choose "environmental protection", $10 \%$ of people have other demands. The data team will reflect this requirement to the research and development department and materials department, so that they pay attention to consumer requirements. The analysis and research of these data will help enterprises to formulate and analyze the next step of marketing strategy. Improving product design, 


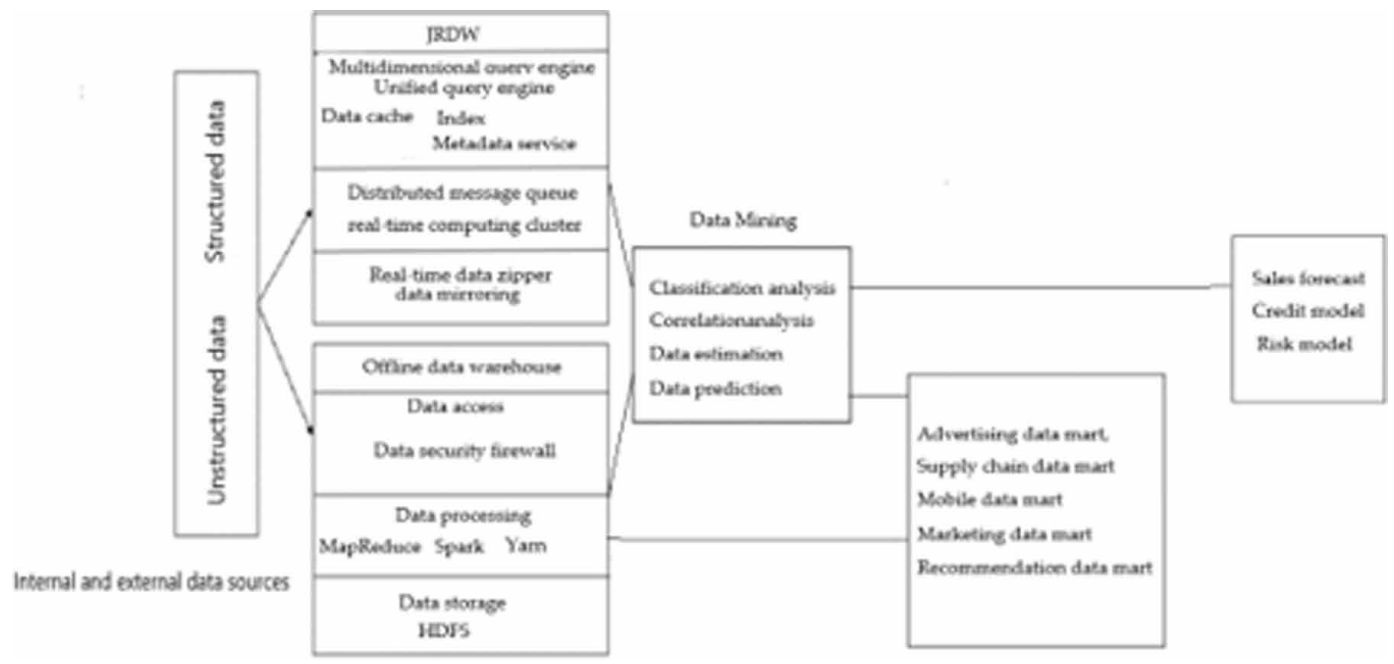

product pricing, and customer service based on user evaluation data is an important way to achieve product and service innovation. Artificial intelligence technology is ready to go, and it will make a huge contribution to the transformation and development of the industry(Zhang, 2018; Zhang, 2019).

\section{The Role of Modern Artificial Intelligence in Precision Marketing In-Depth Understanding of Customer Needs and Improve Consumer Satisfaction}

With the development and progress of global digital networks, the use of advanced artificial intelligence technology can better serve customers, discover market opportunities, and expand market opportunities. The main value is reflected in the accurate analysis of customer behavior characteristics and needs. Analysis of customer behavior characteristics and needs is an important basis for achieving accurate marketing. Secondly, artificial intelligence technology can accurately locate customers and personalize accurate recommendations. Omnichannel's path to excellence begins with the digital identity consumer now in control. Consumers chase time, place, place and manner. Conditions that brands must interact with them. This changed the game and the work we did. As marketers, we must change. Mastering Personalization Personalization is the name of the game, and that's why marketers are stuck with so much data and segmentation. But personalization has become the customer's expectations (perhaps unstated), so we have to join in. Now brands are building relationships with their customers and earning their trust.

The best way to gain this trust is to show your customers how much you know about them and make smart expectations with product recommendations. If a brand knows you well every time you visit their website or receive an email, you will see for the products you prepare, we must create experience that proves that we understand the audience's style, shopping preferences and personal preferences, and the finest details. We can inject website (product) recommendations into our strategy of building trust with our customers. (Zhang, 2019) With AI-enabled technology, product recommendations can be automatically populated via simple emails or website widgets, and of course also available through customer data. Precision marketing under AI technology can accurately target users to pass product information, maximize marketing benefits, reduce consumer satisfaction costs, facilitate customer purchases, increase shopping convenience, achieve two-way communication with customers, and improve in order to increase the total customer value, a stable corporate loyal customer base has been established. 


\section{Personalized Marketing Advantages to Improve Market Competitiveness}

Use AI for personalized marketing. Over time, marketing requires more sophisticated personalized analysis. When we learn more about our customers or potential customers and fill in information about that person's needs, budgets and interests, we A unique, personalized experience can be created to educate and please this person. The more we know about consumer groups, the more competitive advantages we can achieve. Now we are entering the era of hyper-personalization, which can not only be personalized through characters, profiles, or traces of bread crumbs left by people on your website, but also through a large number of user details and signals, and through The machine analyzes and operates, thereby attracting customers to buy and generate buying behavior, and seize the dominant market position (Fischer, 2007; Ni,2018).

The company controls how, what, when and where the consumer experiences and interacts with the brand. Consumers are becoming aware of new products in magazine or newspaper ads. They show advertisers' compelling commercials on their favorite TV shows. In the digital age, at first, it slowly started. As the computer scaled down, the driving force for growth and the popularity index increased, the speed of change accelerated, and the Internet became a place for brands to show their products to consumers. The phone has transformed into an always-connected global beacon, and it has now become a practical extension of our own, with consumers beginning to use social media as a primary means of interacting with each other and with brands. The successful digital age of having email in the mobile first world is also the "information" era, with the amount of available information increasing and media technology changing. As consumers are more willing to share data, consumers also expect more. The traditional advertising model is not obvious in sales, especially the rapid development of the Internet, and the role of TV advertising has weakened. The era of AI marketing has arrived. It has helped marketing appear in front of the general public with a more vivid image, helped managers and marketers make better decisions, reduced spending costs, shortened the distance with customers, and increased Customer interaction and innovative technical methods help marketing achieve the best results.

\section{APPLICATION OF ARTIFICIAL INTELLIGENCE IN PRECISION MARKETING STRATEGY}

\section{The Urgent Problems of Artificial Intelligence in Precision Marketing}

From the widely discussed marketing status report, more than half $(51 \%)$ of marketers are using artificial intelligence in some form, while another quarter are planning to test it in the next two years because Many marketers (and entire business leaders) are confused as to which technologies are truly driven by artificial intelligence and rely solely on advanced algorithms and analytics, and many marketers are confused as to which technology is truly driven by artificial intelligence. As Luis Perez-Breva, project leader of the MIT Innovation Team and research scientist at the MIT School of Engineering, explains, "Most of the artificial intelligence in the retail industry is not artificial intelligence." He said many people "confuse analysis Plenty of data for artificial intelligence and profiling customers. Throwing data on the machine does not make the machine (or anyone) smarter. The promise of AI is often referred to as large-scale correlation. Machines can handle large data sets and Data, structured and unstructured data, and optimized decision making in ways that people who can implement algorithms cannot. (Paniagua-Vega,2019; Ivanaj,2019) Perhaps most importantly, in AI-enabled systems, machines can learn and improve without input.

The data shows that the current level of China's artificial intelligence technology is unevenly distributed, and the cost of technological development is still relatively high. Enterprises that mainly use artificial intelligence technology are distributed in developed regions. The technology of artificial intelligence has not been universally applied, and it should be taken seriously by various regions. 
In the era of the digital economy, consumer information is very important, and companies are managing consumer information responsibly, but some companies seem to be processing this information in an irresponsible or even reckless manner. Many online and offline companies Neither has adequately addressed consumer privacy concerns. The entire industry must do better. For every business, privacy should be a basic consideration, as important as tracking cost-benefit or strategic planning. In modern times, the application of the concept of privacy is by no means straightforward. Consumers live in a world where their buying behaviors, online browsing habits, and other online and offline behavior information are collected, analyzed, synthesized, used, and shared, and these are often carried out instantaneously. Some companies will use partner technology to obtain customer privacy, steal user privacy from the technology side, and sell to third-party companies.

According to the report, under the legal supervision, there is a problem that the privacy protection of customers in the current era of big data is not very operable and the relevant provisions are too principled. In addition, customer privacy issues under big data, and the scope of protection is not well defined, leading to the failure to fully protect customer privacy and security (Zhu, 2019; Monhan, 2004).

Consumers browse products through webpages, and the background will summarize customer purchase information based on the browsing history, summarize purchase habits, and push many similar products. In fact, many are not actually demanded by consumers today. Even many product pushes will cause customer dissatisfaction. When the user's positioning goals are not clear, the advertising content will not only make customers feel aesthetic fatigue, affect the customer's advertising experience, but also affect the company's perception of consumers Image (Singh, 2018).

\section{Solution to the application of Artificial Intelligence Technology in Precision Marketing}

Modern artificial intelligence technology-driven marketing will allow marketers to change the actual work they are doing, instead of spending hours and days splitting contacts, saving more costs. By "embedding" artificial intelligence and machine learning in your marketing platform, you can make intelligent decisions. This type of technology is based on the vast amount of customer data you have and starts to understand each of your customers as an individual, which will allow you Expand personalization. Technology is driving our role forward, enabling us to refocus our strategy, content and creative projects. The state should give more support in technology to reduce the application cost of artificial intelligence technology. Governments in various regions should pay more attention to artificial intelligence technology, cultivate more talents, provide a better learning environment, and relevant enterprises should also be aware of labor. The necessity of intelligent technology for corporate progress and development. Using AI technology to deal with corporate marketing issues can improve the efficiency of operations, bring better experience to customers, and use artificial intelligence technology to achieve large-scale personalization for marketing purposes. Make future artificial intelligence technology apply to online and offline life (Hamidi, 2018).

When collecting and unifying all customer data, enterprises should abide by the principles of protecting data and respecting privacy. Only by truly thinking about customer safety can they win the basic trust of customers. Consumers should also strengthen their precautionary awareness, pay attention to protecting personal privacy, and understand their security when entering personal information. Secondly, the Ministry of Industry and Information Technology should also strengthen the privacy protection supervision of related industries, use policies and regulations, and severely punish acts that violate laws and regulations (Chin, 2003).

Precision marketing under AI technology can instantly feedback to merchants through real-time records browsed by users, and push to consumers the product information required. According to the different tags of each user, age and gender are differentiated to use different media to push product information. Personalized advertising content. In this way, our email sending frequency is exactly how often users open their mailboxes, which means that the first email that users see every time they 
open their mailbox is ours, and the customized email content can also bring great benefits to users. Good receiving experience. In the case of unclear personalization of user information, it should be avoided to disturb the consumer's impression of the product brand. Summarize again and again based on repeated feedback information to optimize the user's information base, achieve the purpose of dissemination, and realize the value of dissemination (Wei, 2019).

According to Accenture research, AI has the potential to increase the economic growth rate of all industries by $1.7 \%$ and increase productivity by $40 \%$ or more by 2035 . Operators must use advanced technology to effectively carry out product research and development, promote the planning and construction, operation and maintenance, and data operation of related IT systems, and optimize business models and improve marketing service capabilities as the main entry points, and output precision marketing products to the society. Become a leader in digital services.

In data analysis and mining, IBM's Watson system is a typical success. Watson system does not need to be connected to the Internet, it needs $15 \mathrm{~T}$ data, and it has a strong understanding ability. Data analysis and mining are in the industry. In terms of application, it fully reflects the advantages of artificial intelligence. For example, the financial industry prevents loss and fraud from a large amount of data in advance, and e-commerce can learn about consumption habits from customers' browsing records. This kind of work first deals with a lot of data. At present, because of the artificial intelligence algorithm's complex data, it is difficult to achieve results by handing the data to them for processing. At this time, the measures taken can only be a combination of human and artificial intelligence, and the data analyst extracts some elements from the data to determine the direction and scope and use artificial intelligence technology to calculate the results. Such behavior may need to be repeated many times to get accurate results and achieve the purpose of use. At the same time, people need to "communicate" with technology in combination. In the future, with the advancement of technology, artificial intelligence technology will be well used in all walks of life and become a good partner for human work.

Companies used to control the consumer experience and how they interact with brands, content, time and place, and now consumers are beginning to realize new products in magazine or newspaper ads, and they show advertisers' convincing on their favorite TV shows Commercial advertising, from a brand perspective, everything is systematic and the perfect plan. They decide what consumers know, want and demand in stores, but then the digital age. At first, it slowly started. As the computer scaled down, the growth momentum and popularity were exponential, and the speed of change accelerated. The Internet has become a place where brands show their products to consumers, and the phone has transformed into an always-connected global beacon, which has now become our own practical extension. Consumers have started using social media as the main means of interacting with each other and interacting with brands. The successful digital age of having email in the mobile first world is also the "information" era. The amount of available information has increased, and consumers are expecting more as they are more willing to share data. For those who give a lot, expect a lot. All this makes our business harder and more demanding. The challenge we face is to turn a lot of data into unique, personalized messages for individuals. But with so much data and so many tools, it feels like an impossible task. We are completely changing our role through AI. In order to adapt to the growing needs of our customers to achieve more personalization, we are not only doing change, but what we are doing. Customers want to get personalized messages with content, products, and offers specifically tailored to them, with adjustments to multiple channels.

\section{CONCLUSION}

Artificial intelligence technology will help focus on the strategy behind winning repeat customers, rather than crafting an independent experience for each customer. The final idea of Personalization is no longer optional. Those brands that embrace the future, including artificial intelligence marketing, will win the favor of consumers and have sustained long-term success. Those who ignore the shift in 
consumer expectations will continue to be trapped in data rather than empowered by data. Injecting machines into marketing will help open up a new era and unleash a creative renaissance in the way we work. In homogeneous competition, winning differentiated advantages must reflect the strengths in customer service. Artificial intelligence technology can provide marketers with accurate target customer groups, instantly and accurately find customer need, and improve customer services. Quality. Artificial intelligence technology provides better development for precision marketing. At present, China has further set up a leading R \& D center on the development of artificial intelligence technology. In the future, there will be greater demand for relating talents and technologies. It is important to cultivate relevant talents. The advancement of artificial intelligence technology in the future will have profound significance for China's marketing industry and the development of all industries.

\section{ACKNOWLEDGMENT}

The study was supported by Major Projects of Applied Research on Philosophy and Social Sciences in Colleges and Universities of Henan Province (Project Number: 2018-YYZD-10); Special Topic for Policy Research in Henan Pilot Free Trade Zone (Project Number: 2019-ZM-T26-03); Innovation Fund for Doctoral Postgraduates of North China University of Water Resources and Electric Power. 


\section{REFERENCES}

Canevelli, M., Bruno, G., Grande, G., Quarata, F., Raganato, R., Remiddi, F., Valletta, M., Zaccaria, V., Vanacore, N., \& Cesari, M. (2019). Race reporting and disparities in clinical trials on Alzheimer's disease: A systematic review. Neuroscience and Biobehavioral Reviews, 101, 122-128. doi:10.1016/j.neubiorev.2019.03.020 PMID:30946856

Chang, K. C., \& Seow, Y. M. (2019). Protective Measures and Security Policy Non-Compliance Intention: It Vision Conflict as a Moderator. Journal of Organizational and End User Computing, 31(1), 1-21. doi:10.4018/ JOEUC.2019010101

Chen, J. F., Chakraborty, J., Menzies, T., Clark, P., Haverlock, K., \& Cherian, S. (2019). Predicting breakdowns in cloud services (with SPIKE). Academic Press.

Chin, W. W., Marcolin, B. L., \& Newsted, P. R. (2003). Partial least squares latent variable modelling approach for measuring interaction effects: Results from a Monte Carlo simulation study and an electronic-mail emotion/ adoption study. Information Systems Research, 14(2), 189-217. doi:10.1287/isre.14.2.189.16018

Fischer, E., \& Reuber, R. (2007). The good, the bad, and the unfamiliar: The challenges of reputation formation facing new firms. Entrepreneurship Theory and Practice, 31(1), 53-75. doi:10.1111/j.1540-6520.2007.00163.x

Hamidi, H., \& Jahanshahifard, M. (2018). The Role of the Internet of Things in the Improvement and Expansion of Business. Journal of Organizational and End User Computing, 30(3), 24-44. 10.4018/JOEUC.2018070102

Ivanaj, S., Nganmini, G. B., \& Antoine, A. (2019). Measuring E-Learners' Perceptions of Service Quality. Journal of Organizational and End User Computing, 31(2), 83-104. 10.4018/JOEUC.2019040105

Kim, H. (2019, May). Comparative evaluation of molecular methods for the quantitative measure of torquetenovirus viremia, the new surrogate marker of immune competence. Journal of Medical Virology, jmv.25488. Advance online publication. doi:10.1002/jmv.25488

Kumar, R., Singh, S. P., \& Lamba, K. (2018). Sustainable robust layout using Big Data approach: A key towards industry 4.0. Journal of Cleaner Production, 204, 643-659. doi:10.1016/j.jclepro.2018.08.327

Lin, Q., Qing, S., \& Xue, W. (2019). Study on Operation and Maintenance Resource Scheduling Method of Power Grid Marketing System Based on Sensitivity Clustering. IOP Conference Series: Materials Science and Engineering, 631. 10.1088/1757-899X/631/4/042003

Mayor, P., El Bizri, H. R., Morcatty, T. Q., Moya, K., Solis, S., \& Bdmoer, R. E. (2019). Assessing the Minimum Sampling Effort Required to Reliably Monitor Wild Meat Trade in Urban Markets. Frontiers in Ecology and Evolution, 7, 180. Advance online publication. doi:10.3389/fevo.2019.00180

Mohan, S. (2004). Precision marketing: The new rules for attracting, retaining, and leveraging profitable customers. Akuntansi Pegawai, 93(3), 158-165. doi:10.1111/j.1745-5871.2008.00531.x

Ni, X., Wu, C., \& Zhao, H. (2018). Biased Learning Creates Overconfidence. Journal of Systems Science and Complexity, 31(6), 1603-1617. doi:10.1007/s11424-018-7254-1

O'Connor, D., Mueller-Grabherr, D., \& Hou, D. (2019). Strengthening social-environmental management at contaminated sites to bolster Green and Sustainable Remediation via a survey. Chemosphere, 225, 295-303. doi:10.1016/j.chemosphere.2019.03.035 PMID:30878542

Paniagua-Vega, D., Cavazos-Rocha, N., Huerta-Heredia, A. A., Parra-Naranjo, A., Rivas-Galindo, V. M., Waksman, N., \& Saucedo, A. L. (2019). A validated NMR method for the quantitative determination of rebaudioside A in commercial sweeteners. Journal of Food Composition and Analysis, 79, 134-142. doi:10.1016/j. jfca.2019.02.009

Raad, O., Makdessi, M., Mohamad, Y., \& Damaj, I. (2019). SysMART indoor services: a system of smart and connected supermarkets. Academic Press.

Sharma, M., Sharma, S., \& Singh, G. (2018). Performance Analysis of Statistical and Supervised Learning Techniques in Stock Data Mining. Data, 3. 10.3390/data3040054 
Singh, P., \& Agrawal, R. (2018). A Customer Centric Best Connected Channel Model for Heterogeneous and Iot Networks. Journal of Organizational and End User Computing, 30(4), 32-50.

Wei, C. L., \& Ho, C. T. (2019). Exploring Signaling Roles of Service Providers' Reputation and Competence in Influencing Perceptions of Service Quality and Outsourcing Intentions. Journal of Organizational and End User Computing, 31(1), 86-109. 10.4018/JOEUC.2019010105

Xie, Q., Cheng, G., \& Xu, X. (2019). Research Based on Stock Predicting Model of Neural Networks Ensemble Learning. Computer Engineering and Applications, 55, 238-243. doi:10.3778/j.issn.1002-8331.1807-0294

Yezekyan, T., Marinello, F., Armentano, G., Trestini, S., \& Sartori, L. (2018). Definition of Reference Models for Power, Weight, Working Width, and Price for Seeding Machines. Agriculture-Basel, 8(12), 186. Advance online publication. doi:10.3390/agriculture8120186

Yuning, B., Yeli, L., Qingtao, Z., Yanxiong, S., Linxuan, Y., \& Wei, H. (2020). Research on precision marketing of banking based on improved collaborative filtering algorithms. J. Phys., Conf. Ser. (UK), 1449, 012105-012105. doi:10.1088/1742-6596/1449/1/012105

Zhang, J., Li, D., Hao, Y., \& Tan, Z. (2018). A hybrid model using signal processing technology, econometric models and neural network for carbon spot price forecasting. Journal of Cleaner Production, 204, 958-964. doi:10.1016/j.jclepro.2018.09.071

Zhang, J., Wu, T., \& Fan, Z. (2019). Research on Precision Marketing Model of Tourism Industry Based on User's Mobile Behavior Trajectory. Mobile Information Systems. doi:10.1155/2019/6560848

Zhang, L. X. Z., Mouritsen, M., \& Miller, J. R. (2019). Role of Perceived Value in Acceptance of "Bring Your Own Device" Policy. Journal of Organizational and End User Computing, 31(2), 65-82. 10.4018/JOEUC.2019040104

Zhu, Z., Zhou, Y., Deng, X., \& Wang, X. (2019). A graph-oriented model for hierarchical user interest in precision social marketing. Electronic Commerce Research and Applications, 35, 100845. Advance online publication. doi:10.1016/j.elerap.2019.100845 